
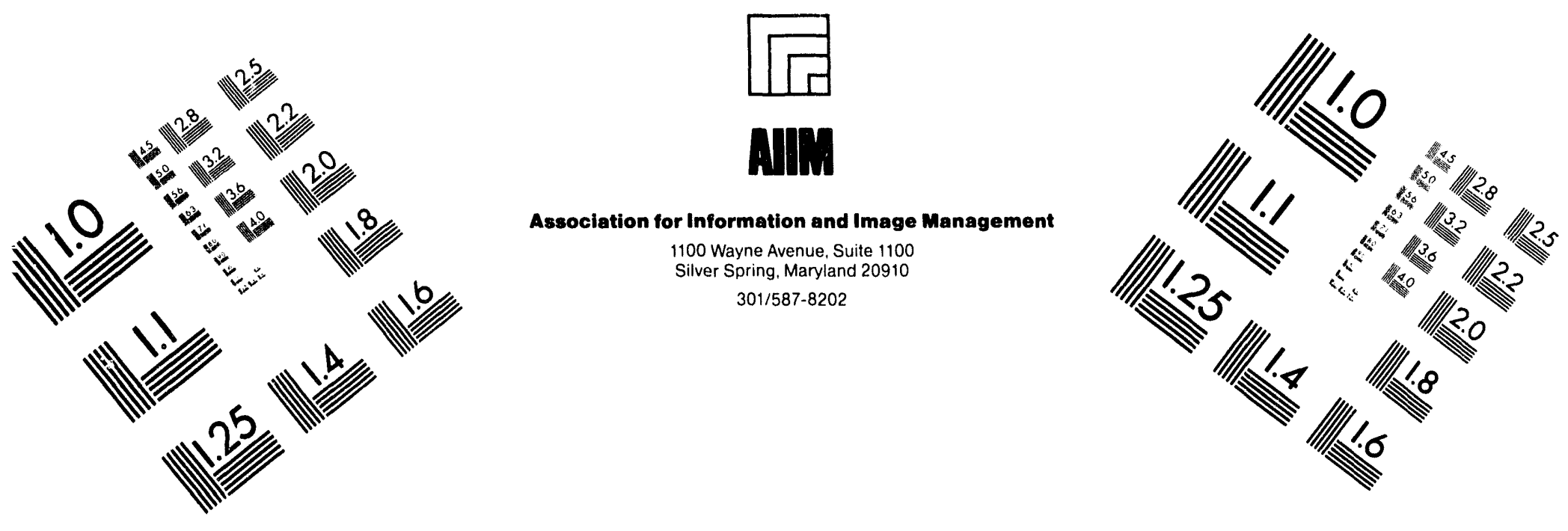

\title{
Centimeter
}

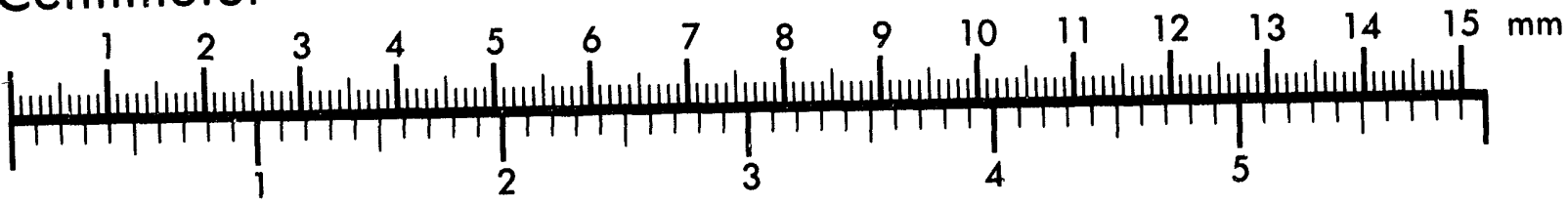
Inches
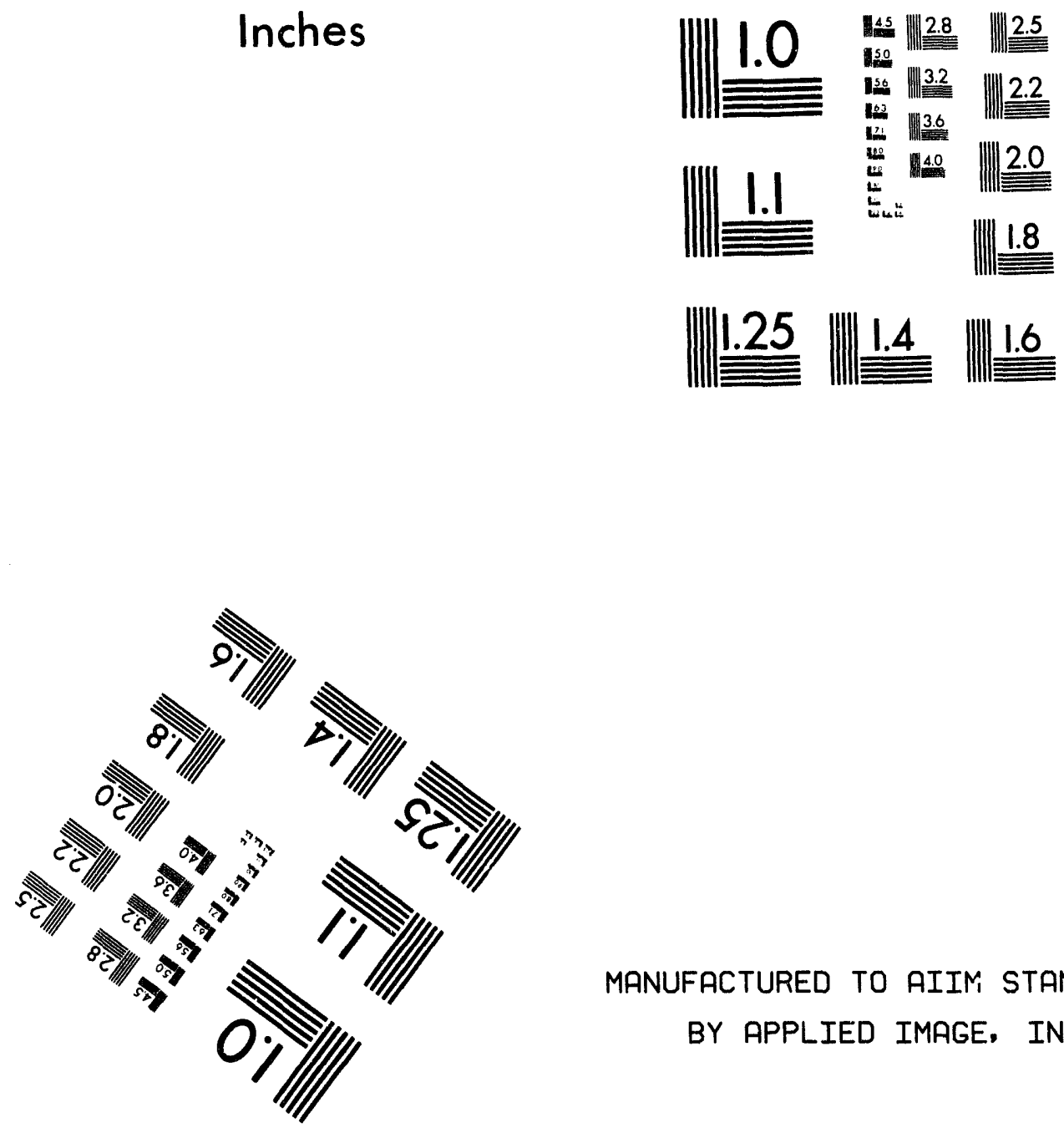

MANUFACTURED TO AIIM STANDARDS

BY APPLIED IMAGE, INC.

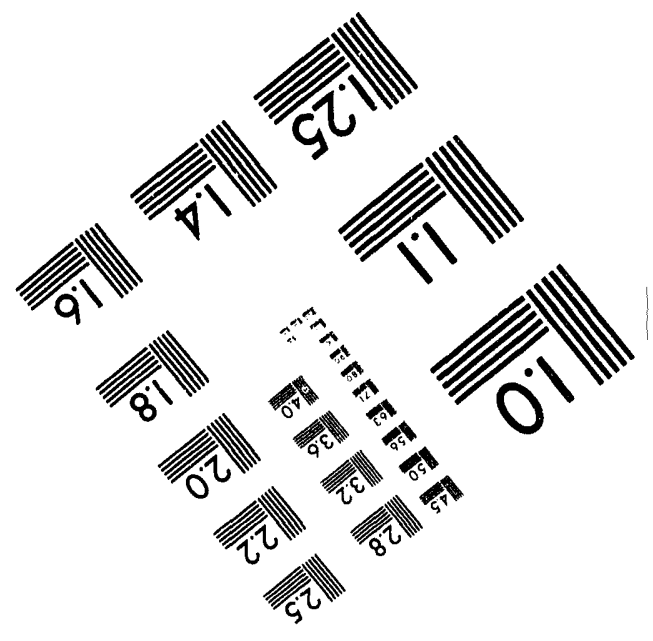



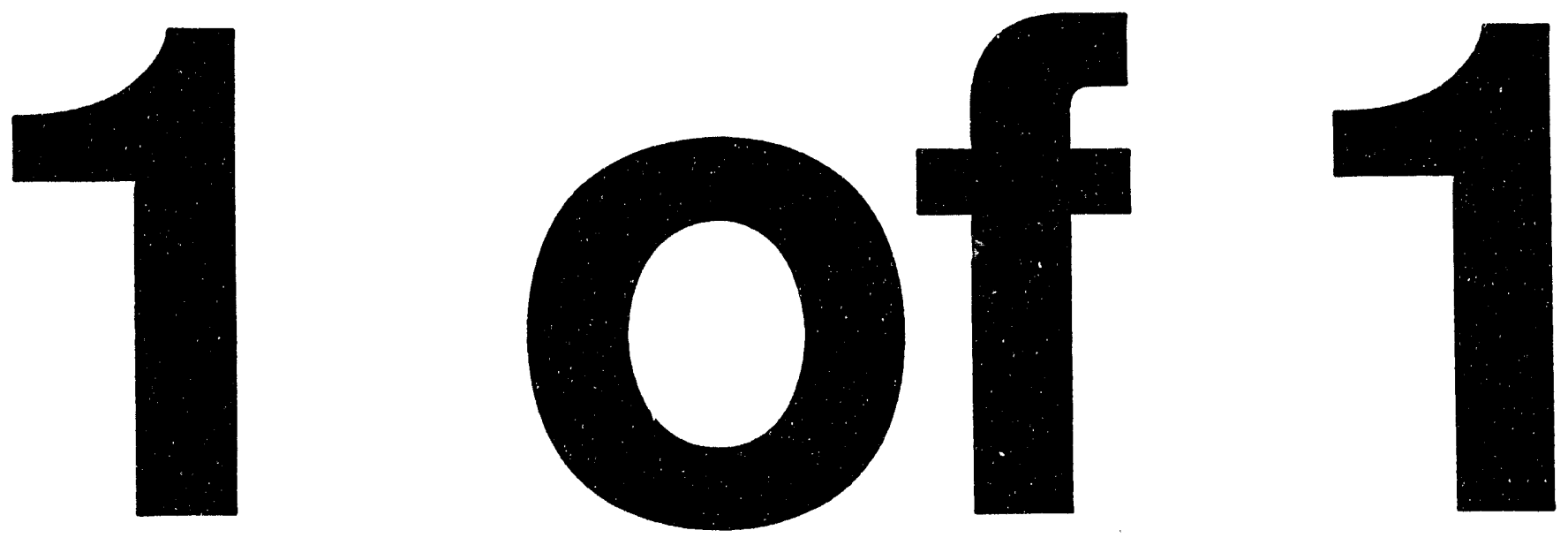
THE EFFECT OF WATER FLOW RATE UPON THE ENVIRONMENTALLY-ASSISTED CRACKING

RESPONSE OF A LOW-ALLOY STEEL

by

L. A. James, G. L. Wire, and W.H. Cullen

U. S. Department of Energy Contract DE-AC11-88PN38014

Joumal Of Pressure Vessel Technology

In Press

RECEIVED

SEP - 6 WOH

OSTI

Operated for the U. S. Department of Energy by WESTINGHOUSE ELECTRIC CORPORATION
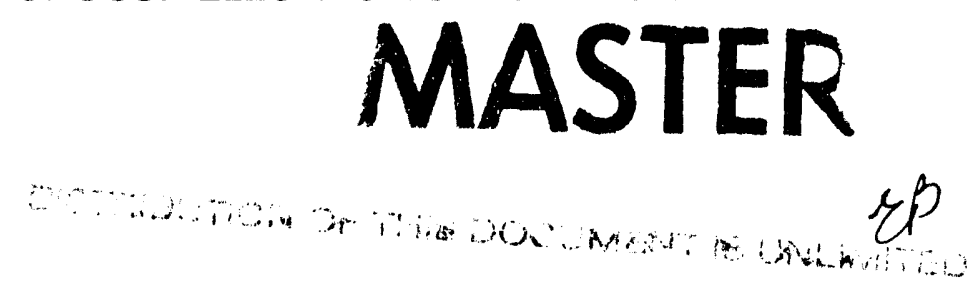


\title{
THE EFFECT OF WATER FLOW RATE UPON \\ THE ENVIRONMENTALLY-ASSISTED CRACKING RESPONSE OF A LOW-ALLOY STEEL
}

\author{
L. A.James* and G. L. Wire \\ Bettis Atomic Power Laboratory \\ Westinghouse Electric Corp. \\ West Mifflin, PA 15122 \\ and \\ W. H. Cuilen \\ Materials Engineering Associates \\ Lanham, MD 20706
}

\begin{abstract}
The effect of water flow rate upon the environmentally-assisted cracking (EAC) response of a high-sulfur ferritic steel was studied at a temperature of $243^{\circ} \mathrm{C}$. In contrast to earlier studies which employed compact-type specimens, this study employed relatively large tight semielliptical surface cracks tested under generally linear-elastic conditions. Flow velocities parallel to the crack as low as $1.58-1.84 \mathrm{~m} / \mathrm{s}$ were effective in mitigating EAC.
\end{abstract}

* Fellow ASME 


\section{THE EFFECT OF WATER FLOW RATE UPON \\ THE ENVIRONMENTALLY-ASSISTED CRACKING \\ RESPONSE OF A LOW-ALLOY STEEL}

\section{INTRODUCTION}

The fatigue crack propagation (FCP) response of ferritic pressuri vessel and piping steels has been a subject of continuing research interest since the pioneering work of Kondo (1) showed that such steels could be susceptible to environmentally-assisted cracking (EAC) in elevated temperature aqueous environments. Kondo, studying ASTM A302-B steel in a Boiling Water Reactor (BWR) environment at temperatures of $200^{\circ} \mathrm{C}$ and $260^{\circ} \mathrm{C}$, demonstrated that, under certain conditions, FCP rates could greatly exceed those that would normally be expected in an air environment under the same conditions. Since Kondo's early work, many scores of publications have addressed EAC in both BWR and Pressurized Water Reactor (PWR) environments. The result of this work is that the EAC process is reasonably well characterized for these environments and, more importantly, an understanding of the mechanisms responsible for EAC has emerged.

A number of factors have been shown to influence EAC susceptibility, and these will be reviewed briefly herein. However, the effect of water flow rate has been demonstrated to be one of the more important variables in influencing EAC behavior, and the present paper will describe new results on the effect of water flow rate upon EAC response. In contrast to previous studies employing compact-type fracture mechanics specimens, the present study utilized tight semi-elliptical surface cracks that are more representative of cracks encountered in service.

\section{EXPERIMENTAL PROCEDURES}

\section{Material}

The steel employed in this study was a high-sulfur ASTM A302-B steel. As will be discussed later, the sulfur content of a steel is a very important variable in influencing EAC susceptibility, with susceptibility generally increasing with increasing sulfur content. Since the objective of the present study was to investigate the effect of water flow rate on mitigating EAC in a tight natural crack, it was necessary to produce a case of EAC under quasi-stagnant flow in each experiment. Hence, when active water flow rates were introduced, a cause and effect relationship with flow could be established. 
The heat of A302-B steel employed (Heat 21478-10) was previously studied in Reference 2, and consistently exhibited EAC under quasi-stagnant conditions at $243^{\circ} \mathrm{C}$ when tested under loading conditions conducive to EAC. The chemical composition of Heat 21478-10 is shown in Table I. The specimens were machined from a $101.6 \mathrm{~mm}$ plate which had been quenched and tempered with the following heat-treatment: austenitized at $899^{\circ}-927^{\circ} \mathrm{C}$ for four hours, water quenched to $538^{\circ} \mathrm{C}$, and air cooled. The plate was then tempered at $649^{\circ}-677^{\circ} \mathrm{C}$, and then stress relieved at $621^{\circ} \mathrm{C}$ for four hours.

\section{Specimen Desian}

Previous studies on flow rate effects upon EAC have utilized compact-type fracture mechanics specimens. Because the mass transport of sulfides from the crack tip region is an important consideration, the flushing characteristics of compact-type specimens may be quite different from those of more natural semi-elliptica! surface cracks. For this reason, a surfacecracked specimen was developed for these flow rate studies. The details of the specimen development are given elsewhere ${ }^{(3)}$, but the specimen features a semi-elliptical surface crack that forms a "natural" intersection with the free surface; i.e., no machined notches nor electrical-discharge machined slits to provide an easier mass transport path.

The specimen is illustrated schematically in Figure 1. The specimens were oriented such that the surface location of the crack had a T-S orientation*, while the deepest penetration had a T-L orientation:. As discussed in Reference 3, the specimen produces a mixture of linear bending stresses $\left(\sigma_{b}\right)$ and uniform stresses $\left(\sigma_{u}\right)$ in the test section; in the present case, the ratio of maximum bending stress to uniform stress, $\sigma_{b} / \sigma_{u}$, was 5:1. Reference 3 also describes the results of a finite-element stress analysis on this specimen, verifying that the simple assumption of uniform tension plus linear bending is appropriate for this specimen. Therefore, the stress intensity factor $(K)$ solution of Newman and Raju ${ }^{(4)}$ was utilized for these tests. The various test phases on a given spesimen (i.e., quasi-stagnant flow or high flow) were conducted at different applied stress ratios $\left(R=K_{\min } / K_{\max }\right)$ and cyclic frequencies. This produced textural differences on the fracture face that could be measured following each test (specimens were fractured in liquid nitrogen following testing). Therefore, FCP rates were calculated at the deepest point of the crack and the surface location, employing such

\footnotetext{
* See ASTM E616-89 for the crack orientation system.
} 
measurements $(\mathrm{da} / \mathrm{dN}=\Delta \mathrm{a} / \Delta \mathrm{N}$, and $\mathrm{dc} / \mathrm{dN}=\Delta \mathrm{c} / \Delta \mathrm{N})$, where "a" and "c" are the crack depth and half-crack length, respectively.

\section{Water Chemistry}

Deaearated water coniaining $20-60 \mathrm{ml} \mathrm{H}_{2} / \mathrm{kg} \mathrm{H}_{2} \mathrm{O}$ was employed in this study. Dissolved $\mathrm{O}_{2}$ was therefore genelally less than $10 \mathrm{ppb}$. The room temperature $\mathrm{pH}$ was in the range 10.1 to 10.3, while the calculated ${ }^{*} \mathrm{pH}$ at the test temperature of $243^{\circ} \mathrm{C}$ was 7.8 . The room temperatur $\theta$ conductivity ranged between 21 to $84 \mu \mathrm{S} / \mathrm{cm}$. The corrosion potential of the specimen was measured during each test using a $\mathrm{Ag} / \mathrm{AgCl}$ reference electrode. The relationship of Reference 6 was used to correct $\mathrm{Ag} / \mathrm{AgCl}$ measurements to Standard Hydrogen Electrode (SHE) conditions. The potential generally averaged about -0.74 volt (SHE) during both the active flow and quasi-stagnant flow test phases. Water flow rate has been shcwn to influence corrosion potential ${ }^{(5)}$, and it should be noted that the electrode in the present tests, was not located in a region of the specimen that was influenced by flow. The mean value of -0.74 volt (SHE) is in good agreement with similar measurements on several other steels at the same temperature ${ }^{(2)}$ in low-oxygen water.

\section{Autoclave Arrangement and Conditions}

A relatively standard cylindrical autoclave was fitted with a cylindrical extension that accommodated the rather large specimen size $(127 \times 177.8 \times 50.8 \mathrm{~mm})$ as well as providing a nozzle (19.05 mm I.D.) through which flow could be ducted to the specimen from an external pump. The external pump could deliver water flow of up to about 79.5 liters/minute at the specified test temperature, and operated in a recirculating mode. Lower flow rates could be achieved, if desired, by the use of an orifice. Ducted flow was directed across the specimen in a direction parallel to the crack as illustrated schematically in Figure 1. To ensure relatively uniform water streamlines, no significant directional changes were made in the flow duct for a distance of at least ten diameters upstream of the specimen. The flow duct had a small change in cross-sectional area across the specimen: $285 \mathrm{~mm}^{2}$ at the inlet, and $244 \mathrm{~mm}^{2}$ at the outlet. Hence, there was a minor flow velocity gradient across the specimen. The bulk water in the autoclave also recirculated at a rate of $125 \mathrm{ml} / \mathrm{min}$, producing an autoclave volume exchange approximately every 2.7 hours. The inlet to the external active flow loop drew water from the general autoclave inventory.

"Calculated using MULTEQ $\bullet$ (Electric Power Research Institute). 


\section{RESULTS AND DISCUSSION}

\section{Review of Previous Results}

Before discussing the present results, it is useful to review briefly several items: 1) the mechanisms believed responsible for EAC, 2) "time-domain" FCP modeling, and 3) previous results on the effect of water flow rate upon EAC.

In general, two models have been proposed for EAC: anodic slip-dissolution ${ }^{(7)}$ (ASD) and hydrogen-assisted cracking ${ }^{\left({ }^{()}\right)}(\mathrm{HAC})$. The former is thought to be more dominant at relatively high corrosion potentials (i.e., high dissolved oxygen), while the latter is thought to be more dominant at lower corrosion potentials (i.e., low dissolved oxygen). The two different mechanisms are not mutually exclusive, and indeed both may occur at the same time; as pointed out in Reference 9, the anodic dissolution reaction is a necessary counterpart to the cathodic reaction which is responsible for hydrogen production. In a practical way, the distinction between the two mechanisms may not be crucial, since both mechanisms appear to be subject to the same rate-controlling process: the supply of sulfides to the crack tip versus the loss of suliides from the crack tip.

It is well established that sulfide ions in the vicinity of the crack tip play an important role in influencing EAC behavior. The sulfides may be present in the water as an impurity ${ }^{(10.11)}$, or in the steel as an impurity ${ }^{(8,10,12-14)}$. In the latter case, manganese sulfide (MnS) inclusions in the steel readily dissolve in hot water ${ }^{(12,15)}$, and as a growing crack intersects such particles, they become dissolved, and hence create a continuing supply of sulfide ions.

The results of this study are presented in the "time-domain" format first introduced by Shoji ${ }^{(16.1 n}$ and coworkers. It is well established that the rupture of oxide films at the crack tip is a necessary step in the EAC process ${ }^{(13)}$ for both ASD and HAC mechanisms, and that the oxide rupture rate is dependent upon the crack tip strain rate. It has also been posiulated that the crack-tip strain rate represents the mechanical crack driving parameter in the EAC process. Shoji and coworkers ${ }^{(16,17)}$ have suggested that the "time-based air rate" $\left(a_{b}\right)$ is proportional to the crack-tip strain rate, and is a convenient method of characterizing the mechanical crack driving parameter. $a_{b}$ is merely the mean FCP rate (da/dN) expected for a given steel in room temperature air at a given level of $\Delta K$ and $R$, divided by the load rise-time $\left(T_{r}\right)$. Eason ${ }^{(19)}$ developed an expression for the FCP behavior of a variety of pressure vessel steels in air: 


$$
\frac{d a}{d N}=7.87 \times 10^{-8}\left(\frac{\Delta K}{2.88-R}\right)^{3.07}
$$

where $\mathrm{da} / \mathrm{dN}$ is in $\mathrm{mm} /$ cycle, and $\Delta K$ is in $M P a / m$. The time-based air rate, $a_{b}$, is therefore the value of da/dN, from Equation [1] divided by $T_{r}$. In a similar fashion, the "time-based environmental rate", $\hat{a}_{e}$, is the experimentally-observed value of $d a / d N$, again divided by $T_{r}$. In such a plot, environmentally-enhanced cracking manifests itself by plotting significantly above the mean air line.

Several previous investigations have studied the effect of water flow rate upon stresscorrosion cracking (SCC) under static loadings ${ }^{(20-22)}$, or EAC under cyclic loadings ${ }^{(10,23-25)}$. In all cases except one (which will be discussed later), "high" water flow rates either reduced or eliminated SCC or EAC. Examples of flow rate mitigation of EAC in cyclic tests are given in Figures 2-4. Also plotted in Figures $2-4$ is the EAC model of Reference 26. The results shown in Figures 2 and 3 were generated using 25 mm-thick compact tension specimens, while those shown in Figure 4 employed a face-grooved tapered double-cantilever-beam specimen $25 \mathrm{~mm}$ thick (21.2 $\mathrm{mm}$ thick at crack plane). It is clear from Figures $2-4$ that "high" flow conditions virtually eliminated EAC, compared to "low" flow conditions which did not. However, the flow conditions for these experiments were not always well characterized. The Reference 10 test (Figure 2) employed approximately 45 liter/minute flow thorough an autoclave of unspecified volume and internal arrangement for the "high" flow conditions. Flow conditions for the Reference 24 tests (Figure 3) were completely unspecified except for the descriptions of "high" and "low". The Reference 25 tests (Figure 4) were subjected to a flow of 13.3 liter/minute that produced an exit velocity from the $7 \mathrm{~mm}$ diameter supply tube of 5.77 meter/second $(\mathrm{m} / \mathrm{s})$ for the "high" flow conditions.

The one previous result that did not exhibit mitigation of EAC was reported in Reference 23. Four $50.8 \mathrm{~mm}$ thick compact tension specimens (utilizing four different steels with sulfur levels ranging from $0.004 \%$ to $0.025 \%$ ) were tested in series in a "daisy chain" arrangement. A manifold, delivering a total flow of 0.83 liter/minute, with four $12.7 \mathrm{~mm}$ diameter outlets delivered calculated flow velocities of $0.051,0.046,0.040$, and $0.031 \mathrm{~m} / \mathrm{s}$ (top outlet to bottom outlet, respectively). The outlet tubes were located approximately $20 \mathrm{~mm}$ in front of, and at an angle to, the front face of each specimen. Flow conditions infringing upon the front face and proceeding down into the notch root (about $38 \mathrm{~mm}$ from the front face) are unknown, but flow velocities at the crack mouths were undoubtedly relatively low. It is 
therefore not surprising that EAC was not reduced by water flow during the Reference 23, tests.

As encouraging as the results illustrated in Figures 2-4 are, they can only be considered as qualitative "proof-of-principle" tests. This is because in most cases, the flow conditions at the crack mouth are not well characterized, or because the mass-transport kinetics involved in flushing sulfides out of a two-dimensional (length and width) crack in compact type specimens may be quantitatively different from those of a more prototypic three-dimensional (length, depth and width) semi-elliptical surface crack.

\section{Results of Present Tests}

Results from three tests conducted on surface-cracked specimens are reported herein. Flow conditions for the three tests are shown in Table II. The first test (Specimen SC-9) was employed to check out the test apparatus and optimize the testing methods; hence, it represents somewhat of a learning experience. Nevertheless, it did reveal one very important point that is worthwhile considering: that the beneficial effect of high water flow rate does not take place instantaneously with the commencement of high-flow conditions. Specimen SC-9 featured a smaller crack size $(a=4.6 \mathrm{~mm}, 2 c=10.4 \mathrm{~mm})$ at the start of high-flow testing than the following two specimens. As shown in Table III, high-flow testing commenced immediately upon the completion of the quasi-stagnant test phase, and two high-flow test phases were employed. The results are given in tabular form in Table IV and plotted in Figure 5. EAC was observed at the deepest point of the crack under quasi-stagnant conditions (denoted as " 1 " in Figure 5), but apparently not at the surface points* based on post-test measurements of $\Delta a / \Delta N$ and $\Delta c / \Delta N$, respectively. The first high-flow test phase (denoted as "2" in Figure 5) exhibited a lesser degree of EAC at the deepest point, and essentially no EAC at the surface. The second high-flow test phase (denoted as " 3 " in Figure 5) did not produce EAC at either location. The "partial" case of EAC observed at the deepest point during the first high-flow test phase suggests that the imposition of high-flow conditions did not result in an instantaneous drop in FCP rates. Rather, this high-flow phase probably started out with EAC, and FCP rates probably continuously dropped throughout the test phase to non-EAC levels as more sulfides were progressively flushed from the crack. The

\footnotetext{
*Optical resolution of $\Delta c$ at the surface was difficult for the quasi-stagnant test phase. Therefore, considerable uncertainty must be attached to the apparent observation of no EAC at the surface under quasi-stagnant conditions.
} 
method of calculating the FCP rate for this increment $(\mathrm{da} / \mathrm{dN}=\Delta \mathrm{a} / \Delta \mathrm{N})$ produces an average of these two different behaviors; hence, a "partial" case of EAC. For this reason, it was decided to incorporate an active flow non-cycling "soak" period in future tests between stagnant and active flow phases (See Table III).

The results for the other two tests at high and moderate flow conditions are illustrated in Figures 6 and 7, respectively, as well as in tabular form in Table IV. Also shown is the mean EAC curve for this heat of A302-B steel (as well as other high-sulfur heats) developed in Reference 2 for a test temperature of $243^{\circ} \mathrm{C}$. This curve is qualitatively similar to the Eason Model ${ }^{(26)}$ shown in Figures 2-4, but differs quantitatively because the Reference 2 curve represents mean EAC behavior at $243^{\circ} \mathrm{C}$ while the Eason Model represents a 95-percent upper bound of $288^{\circ} \mathrm{C}$ data.

As discussed earlier, the first test phase on each specimen featured quasi-stagnant flow; approximately $125 \mathrm{ml} /$ minute recirculating through the autoclave loop (not the high flow loop which was not activated). The purpose was to demonstrate that each specimen could exhibit EAC, and this was indeed observed.

It is clear from Figures 6 and 7 that EAC was observed during the quasi-stagnant flow phases on Specimens SC-10 and SC11. In addition, the FCP rates observed agree very well with rates measured on compact tension specimens reported in Reference 2. It is also apparent from Figures 5 and 6 that both high $(4.60-5.39 \mathrm{~m} / \mathrm{s})$ and moderate $(1.58 \cdot 1.84 \mathrm{~m} / \mathrm{s})$ flow velocities effectively turned off the EAC process in this high-sulfur steel. It is also important to note that the surface cracks employed had relatively large dimensions: at the start of the active flow test phase, Specimen SC-10 had a size of $\mathrm{a}=14.0 \mathrm{~mm}$ and $2 \mathrm{c}=31.0 \mathrm{~mm}$, while Specimen SC-11 had a size of $a=14.7 \mathrm{~mm}$ and $2 C=33.0 \mathrm{~mm}$. It must also be remembered that these were tight natural cracks having no crack-starting notches or slits to aid fluid flow within the crack. Crack-tip and crack-mouth opening displacements were not enhanced by excessive plastic flow, because the maximum uniform plus bending stress at the free surface of the crack was only about sixty percent of the monotonic yield stress at the test temperature. Hence, these experiments represent reasonably severe tests of the ability of water flow parallel to the crack to mitigate EAC in tight natural surface cracks.

It will also be noted in Figures 6 and 7 that, under active flow conditions, the FCP rates at the surface appear to be somewhat lower than those at the point of deepest penetration; they are, in fact, slightly below the mean air line (Eq. [1]). This suggests that the fluid flow was 
sornewhat more effective in flushing sulfides close to the surface than at the deepest point of the crack. This, in turn, suggests that crack aspect ratios $(a / c)$ could develop in proportions other than those predicted by assuming uniform environmental effects along the entire crack periphery. Figure 8 compares the observed crack aspect ratios with those predicted on the basis of uniform environmental effects. Two predicted curves are shown: one assuming that the stress intensity factor range at the free surface $\left(\Delta \mathrm{K}_{\mathrm{c}}\right)$ is fully effective in producing fatigue crack extension (Curve " $A$ "), and the other that assumes that $\Delta K_{c}$ is only partially effective following the suggestions of References 4 and 27 (Curve " $B$ "):

$$
\Delta K_{c, \text { on }}=0.9 \Delta K_{c}
$$

The time-based air rates $\left(a_{b}\right)$ for the surface locations plotted in Figures 6 and 7 were calculated employing Equation [2].

Figure 8 shows that the room temperature air precracking of Specimens SC-10 and SC-11 produced cracks close to that predicted using Equation [2]. However, as the environmental test progressed, it is clear that the crack aspect ratio locii deviate significantly from that predicted for uniform cracking, and in fact approached unity. Note that the deviation occurred in both the quasi-stagnant as well as the active flow test phases. Paragraph G-2120 in Appendix G to Section III of the ASME Boiler and Pressure Vessel Code requires that hypothetical semi-elliptical surface cracks in reactor pressure vessel walls should be assumed to have an aspect ratio of $\mathrm{a} / \mathrm{c}=\mathbf{0 . 3 3 3}$. The present results suggest that actual crack aspect ratios might indeed exceed unity.

The Heat 21478-10 plate had been given a moderate degree of cross-rolling. Hence, the MnS inclusions had an elongated plate-like shape. References 28 and 29 have shown that there is some degree of nonuniformity in FCP rates associated with elongated MnS inclu. sions. Therefore, the aspect ratio locii for the present tests shown in Figure 7 could have three different contributing factors: 1) a mechanical surface retardation effect as suggested by References 4 and 27 and accounted for by Equation [2], 2) differing degrees of environmentally-enhanced cracking at the surface and depth locations, and 3) anisotropy of MnS inclusions. However, whatever the combination of contributing factors, the present results raise a question about the ASME Code Section III aspect ratio assumptions. 
As discussed earlier the occurrence, or non-occurrence, of the EAC mechanism is thought to be the result of the outcome betweeri two competing processes: supply of sulfides by the growing crack intersecting and dissolving MnS inclusions in the steel, versus loss of sulfides from the crack tip by mass transport processes. There are four mass transport processes that may be operative in a crack: 1) diffusion (due to a $S^{\prime}$ ion gradient), 2) ion migration (due to a potential gradient from the crack tip to the crack mouth), 3) fatigue "pumping" (probably effective only at relatively high cyclic frequencies) and 4) convection within the crack due to external fluid flow. These mass transport processes are reviewed in Reference 30 . The relative contributions of each of the above mass transport processes are not presently assessed quantitatively as they apply to the present experiments. It is clear, however, that in the absence of active water flow, the first three mass transport processes were not effective in mitigating EAC in the present tests. However, with the introduction of active water flow, EAC was virtually eliminated. Hence, it is possible to state that active water flow parallel to the crack was extremely effective in mitigating, EAC, and in a qualitative sense, must be considerably more effective than the first three mass transport processes.

\section{SUMMARY AND CONCLUSIONS}

This paper reports the results of two experiments that were conducted to characterize the effect of water flow rate upon the EAC response of a high-sulfur ferritic steel. The conclusions may be summarized as follows:

- Both water flow velocites (parallel to the crack) of $1.58 \cdot 1.84 \mathrm{~m} / \mathrm{s}$ and $4.60-5.39$ $\mathrm{m} / \mathrm{s}$ were effective in eliminating the EAC process after the process had been fully activated in earlier quasi-stagnant test phases.

- The experiments described represent relatively severe tests of the ability of moderate to high parallel flow velocites to mitigate EAC because relatively large tight natural semi-elliptical cracks were tested under generally linear-elastic conditions.

- Crack aspect ratios (a/c) that developed under both quasi-stagnant and active-flow test phases deviated from those normally observed in an air environment (i.e., uniform environmental conditions around the crack periphery). The crack aspect ratios approached unity compared to the ASME Code assumption of $a / c=0.333$. 


\section{ACKNOWLEDGEMENT}

This work was performed under a U. S. Department of Energy Contract with the Bettis Atomic Power Laboratory, a unit of the Westinghouse Electric Corporation.

\section{REFERENCES}

1. T. Kondo, T. Kikuyama, H. Nakajima, and M. Shindo, "Fatigue of Low-Alloy Steels in Aqueous Environment at Elevated Temperatures," Mechanical Behavior of Materials. Proceedings of International Conference on Mechanical Behavior of Materials. Vol 3, The Society of Materials Science, Japan, 1972, pp. 319-327.

2. L. A. James, "The Fffect of Temperature and Cyclic Frequency Upon Fatigue Crack Growth Behavior of Several Steels in an Elevated Temperature Aqueous Environment," Journal of Pressure Vessel Technology, in press, (WAPD-T-2985).*

3. L. A. James and W. K. Wilson, "Development of a Surface-Cracked Specimen", Theoretical and Applied Fracture Mechanics, submitted for publication, (WAPD-T-3001)*.

4. J. C. Newman and I. S. Raju, "Analysis of Surface Cracks in Finite Plates Under Tension or Bending Loads", NASA Technical Paper 1578, December 1979.

5. D. D. Macdonald, H. Song, K. Makela, and K. Yoshida, "Corrosion Potential Measurements on Type 304 SS and Alloy 182 in Simulated BWR Environments", Corrosion, I'ol. 49, No. 1, 1993, pp. 8-16.

6. D. D. Macdonald, A. C. Scott, and P. Wentrcek, "Silver-Silver Chloride Thermocells and Thermal Liquid Junction Potentials for Potassium Chloride Solutions at Elevated Temperatures", Journal of the Electrochemical Society, Vol. 126, No. 9, 1979, pp. 16181624.

* Available from USDOE Office of Scientific Technical Information, P.O. Box 62, Oak Ridge, TN 37831 
7. F. P. Ford and P. L. Andresen, "Corrosion Fatigue of A533B/A508 Pressure Vessel Steels in $288^{\circ} \mathrm{C}$ Water", Proceedings Third International Atomic Energy Agency Specialists' Meeting on Subcritical Crack Growth. NUREG/CP-0112. Vol. 1. 1990. pp. 105-124.

8. P. Combrade, M. Foucault, and G. Slama, "Effect of Sulfur on the Fatigue Crack Growth Rates of Pressure Vessel Steel Exposed to PWR Coolant: Preliminary Model for Prediction of the Transitions Between High and Low Crack Growth Rates, "Proc. Third International Symposium on Environmental Degradation of Materials in Nuclear Power Systems - Water Reactors, 1988, Met. Soc. AIME, pp. 269-276.

9. K. Törrönen, M. Kemppainen, and H. Hänninen, "Fractographic Evaluation of Specimens of A533 B Pressure Vessel Steel", EPRI NP-3483, May 1984.

10. D. R. Tice, "Influence of Mechanical and Environmental Variables on Crack Growth in PWR Pressure Vessel Steels", International Journal of Pressure Vessels and Piping, Vol. 24, No. 2, 1986, pp. 139-173.

11. W. A. Van Der Sluys and R. H. Emanuelson, "Environmental Acceleration of Fatigue Crack Growth in Reactor Pressure Vessel Materials", EPRI TR-102796, Vol. 1, August 1993.

12. J. D. Atkinson and J. E. Forrest, "The Role Of MnS Inclusions in the Development of Environmentally Assisted Cracking of Nuclear Reactor Pressure Vessel Steels," Proceedings of the Second International Atomic Energy Agency Specialists' Meeting on Subcritical Crack Growth, NUREG/CP.0067, Vol. 2, 1986, pp. 153-178.

13. J. H. Bulloch, "Environmental Fatigue Crack Growth Studies: The Effects of NonMetallic Inciusions," Res Mechanica, Vol. 18, 1986, pp. 331-354.

14. J. H. Bulloch, "The Influence of Manganese Sulphide Inclusions on Environmental Assisted Crack Growth Behaviour: Fractographic Aspects, "Theoretical and Applied Fracture Mechanics, Vol. 10, No. 2, 1988, pp. $89-95$ 
15. D. I. Swan and O. J. V. Chapman, "Modeling of Sulfide Inclusion Distributions in Relation to the Environmentally Assisted Cracking of Low-Alloy Steels in a Pressurized Water Reactor Environment", Environmentally Assisted Cracking: Science and Engineering, ASTM STP 1049, 1990, pp. 283-299.

16. T. Shoji, H. Takahashi, M. Suzuki, and T. Kondo, "A New Parameter for Characterizing Corrosion Fatigue Crack Growth," Journal of Engineering Materials and Technology, Vol. 103, No. 4, 1981, pp. 298-304.

17. T. Shoji, H. Takahashi, H. Nakajima, and T. Kondo, "Role of Loading Variables in Environment Enhanced Crack Growth for Water-Cooled Nuclear Reactor Pressure Vessel Steels, "Proc. International Atomic Energy Agency Specialists Meeting on Subcritical Crack Growth, NUREG/CP-0044, Vol. 2, 1983, pp. 143-171.

18. H. Hänninen, K. Törrönen, M. Kemppainen, and S. Salonen, "On the Mechanisms of Environment Sensitive Cyclic Crack Growth of Nuclear Rector Pressure Vessel Steels," Corrosion Science, Vol. 23, No. 6, 1983, pp. 663-679.

19. E. A. Eason, S. P. Andrew, S. B. Warmbrodt, E. E. Nelson, and J. D. Gilman, "Analysis of Pressure Vessel Steel Fatigue Tests in Air," Nuclear Engineering and Desian, Vol. 115, No. 1, 1989, pp. 23-30.

20. P. Hurst, P. Banks, G. Pemberton, and A. S. Raffel, "Stress Corrosion Behaviour of A533-B and A508-III Steels and Weldments and High Temperature Water Environments", Proceedings Second International Symposium on Environmental Degradation of Materials in Nuclear Power Systems - Water Reactors, 1986, American Nuclear Society, pp. 645-655.

21. H. Choi, F. H. Beck, J. Szklarska-Smialowska, and D. D. Macdonald, "The Effect of Fluid Flow on the Stress Corrosion Cracking of ASTM A508 Cl 2 Steel and AISI Type 304 Stainless Steel in High Temperature Water", Corrosion, Vol. 38, No. 2, 1982 , pp 76-85.

22. W. J. Shack, et. al., "Environmentally Assisted Cracking in Light Water Reactors", NUREG/CR-4667, Vol. 5, February 1989. 
23. W. H. Cullen, M. Kemppainen, H. Hänninen, and K. Törrönen, "The Effects of Sulfur Chemistry and Flow Rate on Fatigue Crack Growth Rates in LWR Environments", NUREG/CR-4121, February 1985.

24. H. Kitigawa, K. Komai, H. Nakajima, and M. Higuchi, "Testing Round Robin on Cyclic Crack Growth of Low and Medium Sulfur A533-B Steels in LWR Environments", Trans. Ninth International Conference on Structural Mechanics in Reactor Technology, Vol. F, 1987, pp. 155-160.

25. E. Lenz, N. Wieling, and H. Münster, "Influence of Variation of Flow Rates and Temperature on the Cyclic Crack Growth Rate Under BWR Conditions", Proc. Third International symposium on Environmental Degradation of Materials in Nuclear Power Systems. Water Reactors, 1988, Met. Soc. of AIME, pp. 283-288.

26. E. A. Eason, E. E. Nelson, and J. D. Gilman, "Reactor Pressure Vessel Steel Fatigue Crack Growth Rates in Air and Water Environments," Proceedings Third International Atomic Energy Agency Specialists' Meeting on Subcritical Crack Growth, NUREG/CP. 0112, Vol. 1, 1990, pp. 299-306.

27. I. V. Varfolomeyev, V. A. Vainshtok, and A. Y. Krasowsky, "Prediction of Part-Through Crack Growth Under Cyclic Loading*, Enqineering Fracture Mechanics, Vol. 40, No. 6, 1991, pp. 1007-1022.

28. P. M. Scott and A. E. Truswell, "The Influence of Water Chemistry on Fatigue Crack Propagation in LWR Pressure Vessel Steels", Proceedings of the International Atomic Energy Agency Specialists' Meeting on Subcritical Crack Growth, NUREG/CP-0044, Vol. 2, 1981, pp. 91-126.

29. W. H. Bamford and I. L. W. Wilson, "Characterization of the Environmental Cracking Behavior of High Sulfur Steel Plates", Proceedings of the Second International Atomic Energy Agency Specialists' Meeting on Subcritical Crack Growth, NUREG/CP-0067, Vol. 1, 1986, pp. 317-338.

30. M. J. Psaila - Dombrowski, "Modeling of Crack and Crevice Chemistry in Light Water Reactor Environments", PhD dissertation, Department of Nuclear Engineering, Massachusetts Institute of Technology, 1990. 
TABLE I

CHEMICAL ANALYSIS OF HEAT 21478-10*

$\begin{array}{cccccccccc}\underline{\mathrm{C}} & \underline{\mathrm{Mn}} & \underline{\mathrm{P}} & \underline{\mathrm{S}} & \underline{\mathrm{Si}} & \underline{\mathrm{MO}} & \underline{\mathrm{Cu}} & \underline{\mathrm{Ni}} & \underline{\mathrm{Cr}} & \underline{\text { Remarks }} \\ 0.19 & 1.17 & 0.015 & 0.027 & 0.21 & 0.48 & - & - & . & \text { Mill analysis } \\ 0.19 & 1.29 & 0.026 & 0.024 & 0.22 & 0.55 & - & - & - & \text { Check analysis } \\ 0.21 & 1.34 & 0.021 & 0.027 & 0.22 & 0.51 & 0.22 & 0.23 & 0.14 & \text { Check analysis }\end{array}$

* Percent by weight

TABLE ॥

\section{FLOW CONDITIONS FOR EAC TESTS}

\begin{tabular}{cccc}
$\begin{array}{c}\text { Specimen } \\
\text { Number }\end{array}$ & $\begin{array}{c}\text { Active Flow } \\
\text { Rate (liter/min.) }\end{array}$ & $\begin{array}{c}\text { Active Flow * } \\
\text { Velocity (m/sec.) }\end{array}$ & $\begin{array}{c}\begin{array}{c}\text { Reynolds } \\
\text { Number * }\end{array} \\
\text { SC-9 }\end{array}$ \\
\cline { 2 - 3 } & 78.4 & $4.57-5.33$ & $639,000-667,000$ \\
SC-10 & 78.9 & $4.60-5.39$ & $643,000-674,000$ \\
SC-11 & 27.0 & $1.58-1.84$ & $221,000-230,000$
\end{tabular}

*The lower of the flow velocities and Reynolds Numbers corresponds to the inlet of the flow duct, while the higher corresponds to the outlet. 
TABLE III

SUMMARY OF TEST TIMES

FOR FLOW RATE TESTS

\begin{tabular}{c} 
Specimen \\
Number \\
\hline SC-9 \\
SC-10 \\
SC-11
\end{tabular}

Duration of Stagnant Flow Phase (hours)

118.9

Soak Time Between Stagnant \& Active Flow Phases (hours)

Duration of Active Flow Phase No. 1 (hours)

$$
<<1
$$

228.0

Duration of Active

167.5

100

1022.4

288

648.7

167.5

Flow Phase No. 2 (hours)

233.5

N/A

N/A 
TABLE IV

IABULAR TEST RESULTS

Deepest Point

\begin{tabular}{|c|c|c|c|c|c|c|c|c|c|}
\hline \multirow[b]{2}{*}{$\begin{array}{l}\text { Spec. } \\
\text { No. }\end{array}$} & \multirow[b]{2}{*}{$\begin{array}{c}\text { Teat } \\
\text { Phase }\end{array}$} & \multirow[b]{2}{*}{ R } & \multirow[b]{2}{*}{$\begin{array}{c}T_{1} \\
\text { (gec) }\end{array}$} & & \multirow[b]{2}{*}{$\begin{array}{c}\Delta K_{0} \\
(M P a \sqrt{m})\end{array}$} & \multirow[b]{2}{*}{$\begin{array}{c}d c / d N \\
\text { (mm/sycle) }\end{array}$} & \multirow[b]{2}{*}{$\begin{array}{c}\dot{\vec{a}}_{b} \\
(\mathrm{~mm} / \mathrm{sec} .)\end{array}$} \\
\hline & & & & $\begin{array}{c}\Delta K_{a} \\
(M P a \sqrt{m})\end{array}$ & $\begin{array}{c}\mathrm{da} / \mathrm{dN} \\
(\mathrm{mm} / \mathrm{crcle})\end{array}$ & $\begin{array}{c}d_{b} \\
(m m / s e c .)\end{array}$ & & & \\
\hline SC-9 & quasi-stagnant & 0.7 & 10.3 & 4.94 & 2.52E-5 & $9.45 E-8$ & 5.08 & $3.10 E-6$ & $1.03 E-7$ \\
\hline SC-9 & high flow No. 1 & 0.1 & 51.0 & 14.79 & $4.80 \mathrm{E}-5$ & 2.62E-7 & 16.55 & $8.03 E-6$ & $3.68 E-7$ \\
\hline SC-9 & high flow No. 2 & 0.7 & 10.3 & 4.95 & 2.45E-6 & $9.47 E-8$ & 5.72 & $2.54 E-6$ & $1.48 \mathrm{E}-7$ \\
\hline SC-10 & quasi-stagnant & 0.7 & 50.4 & 7.79 & $1.33 E-4$ & 7.79 E-8 & 9.55 & $1.49 E-4$ & 1.45 E-7 \\
\hline SC-10 & high flow & 0.1 & 104.5 & 25.39 & 5.66E-5 & 6.69 E-7 & 31.98 & 5.27 E-5 & $1.36 \mathrm{E}-\mathrm{b}$ \\
\hline SC-11 & quasi-stagnant & 0.7 & 51.2 & 8.06 & $2.53 E-4$ & $8.50 \mathrm{E}-8$ & 9.80 & $2.53 E-4$ & $1.55 \mathrm{E}-7$ \\
\hline SC-11 & moderate flow & 0.1 & 104.4 & 27.77 & $1.97 E-4$ & 8.82 E-7 & 36.82 & $1.12 E-4$ & $2.10 \mathrm{E}-6$ \\
\hline
\end{tabular}

- Calculation of $\Delta K_{c}$ and $a_{b}$ does not include the 0.9 factor of Eq. [2] 

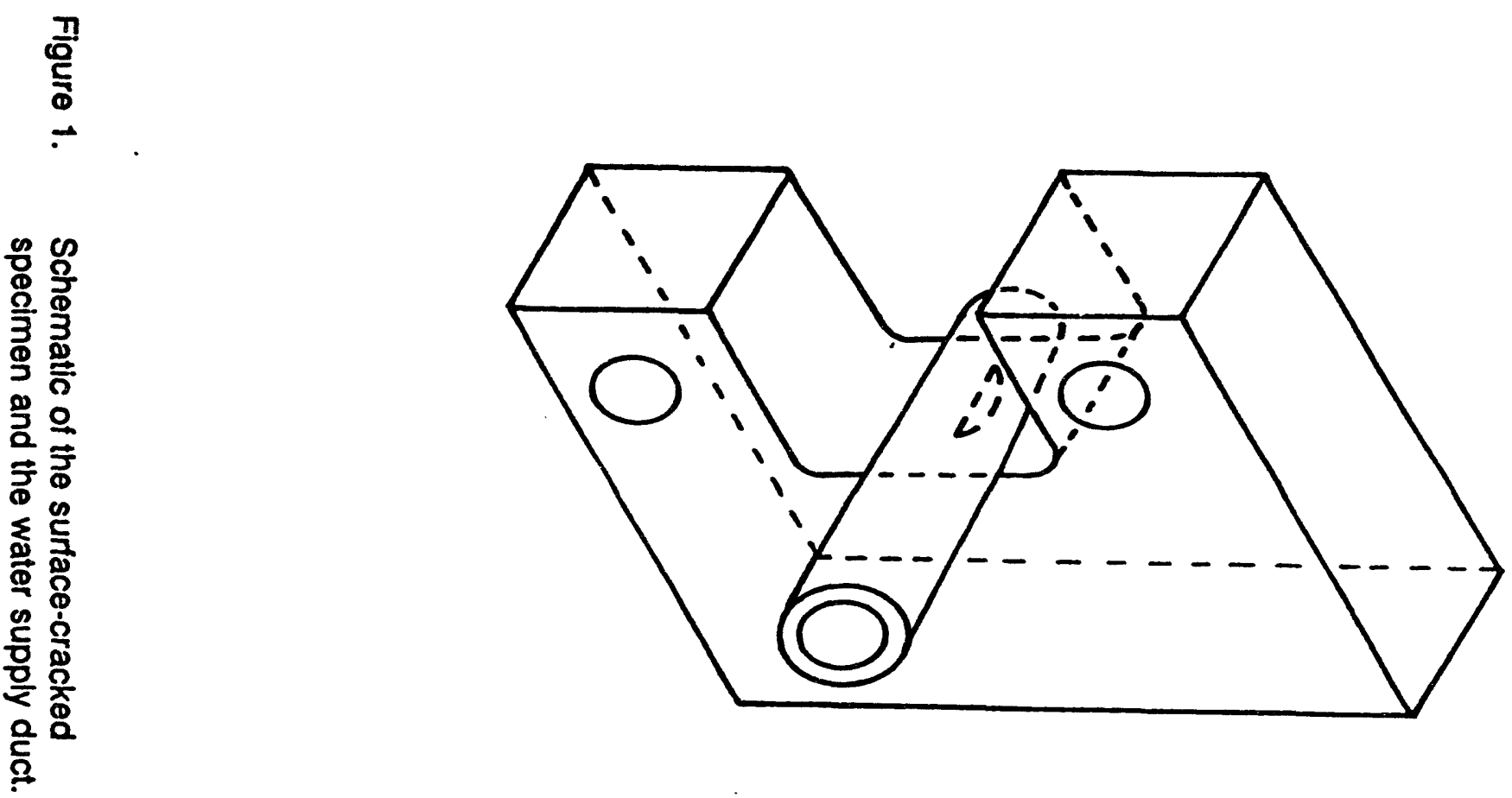


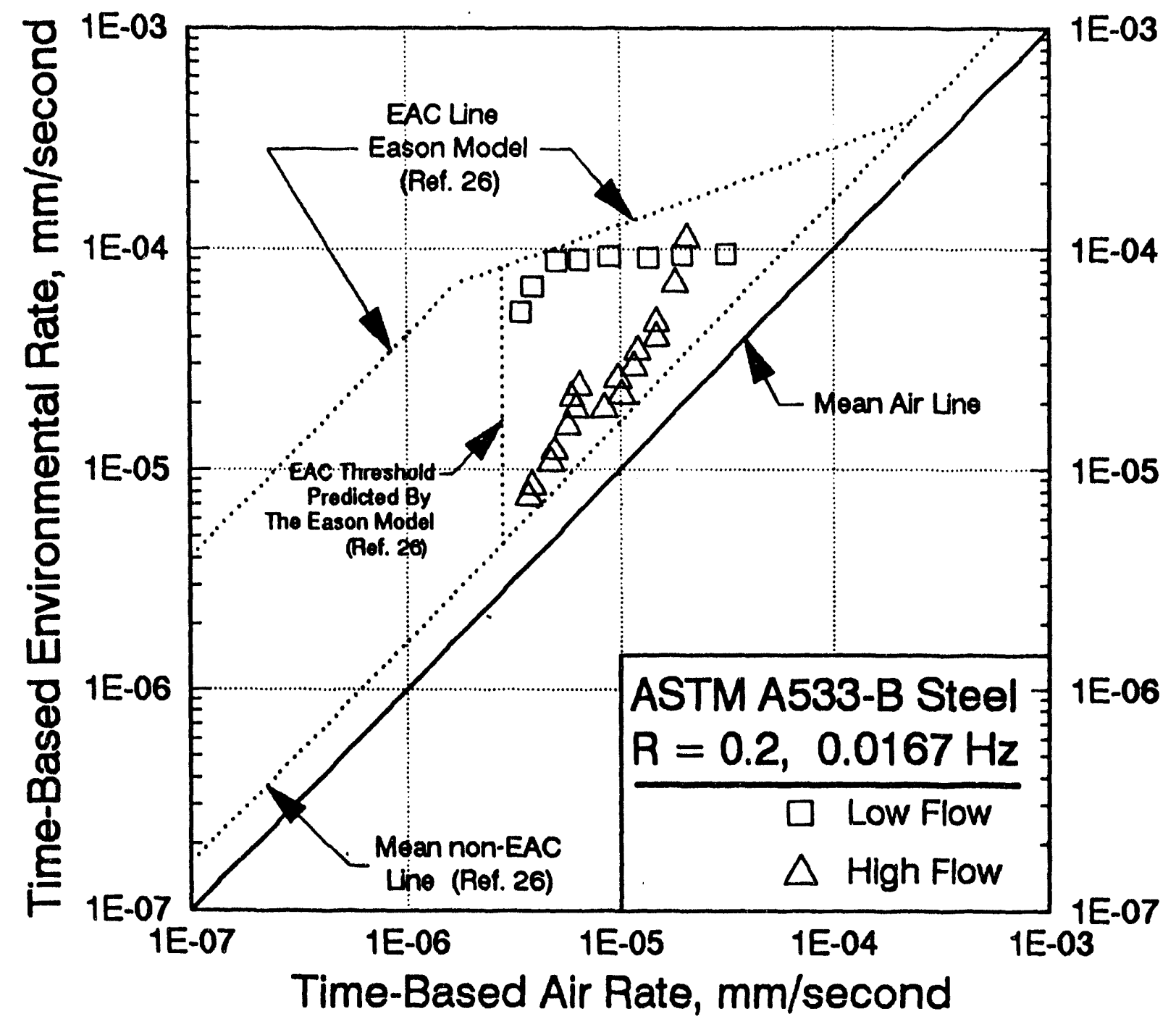

PAPER11

Figure 2. Time-domain plot of results reported in Reference 10 for the effect of water flow rate upon a $0.013 \%$ sulfur A533-B steel in a PWR environment at $288^{\circ} \mathrm{C}$. 


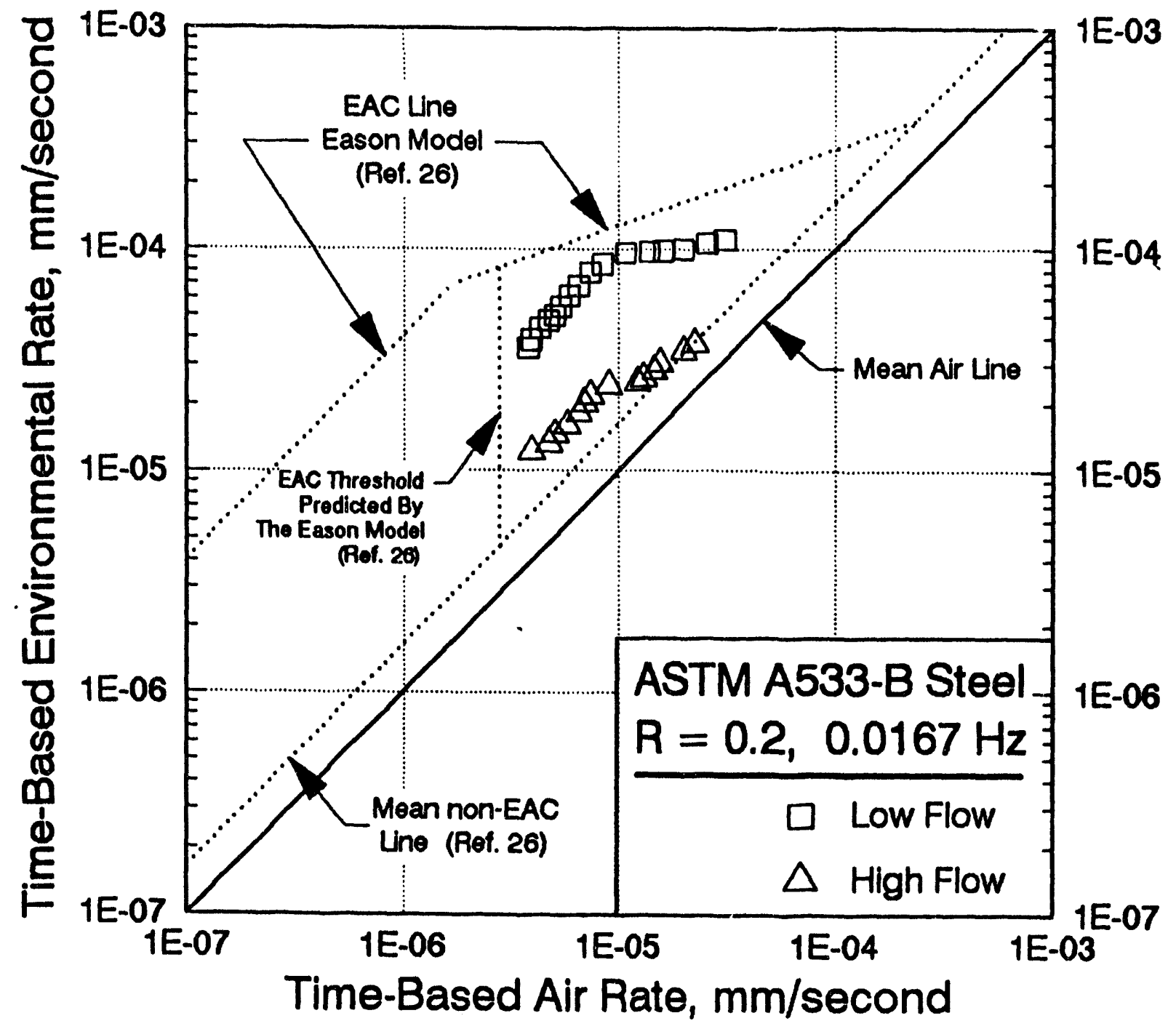

PAPER12

Figure 3. Time-domain plot of results reported in Reference 24 for the effect of water flow rate upon the EAC response of a $0.014 \%$-sulfur A533-B steel in a BWR environment $(200 \mathrm{ppb} \mathrm{O})$ at $288^{\circ} \mathrm{C}$. 
Page 22

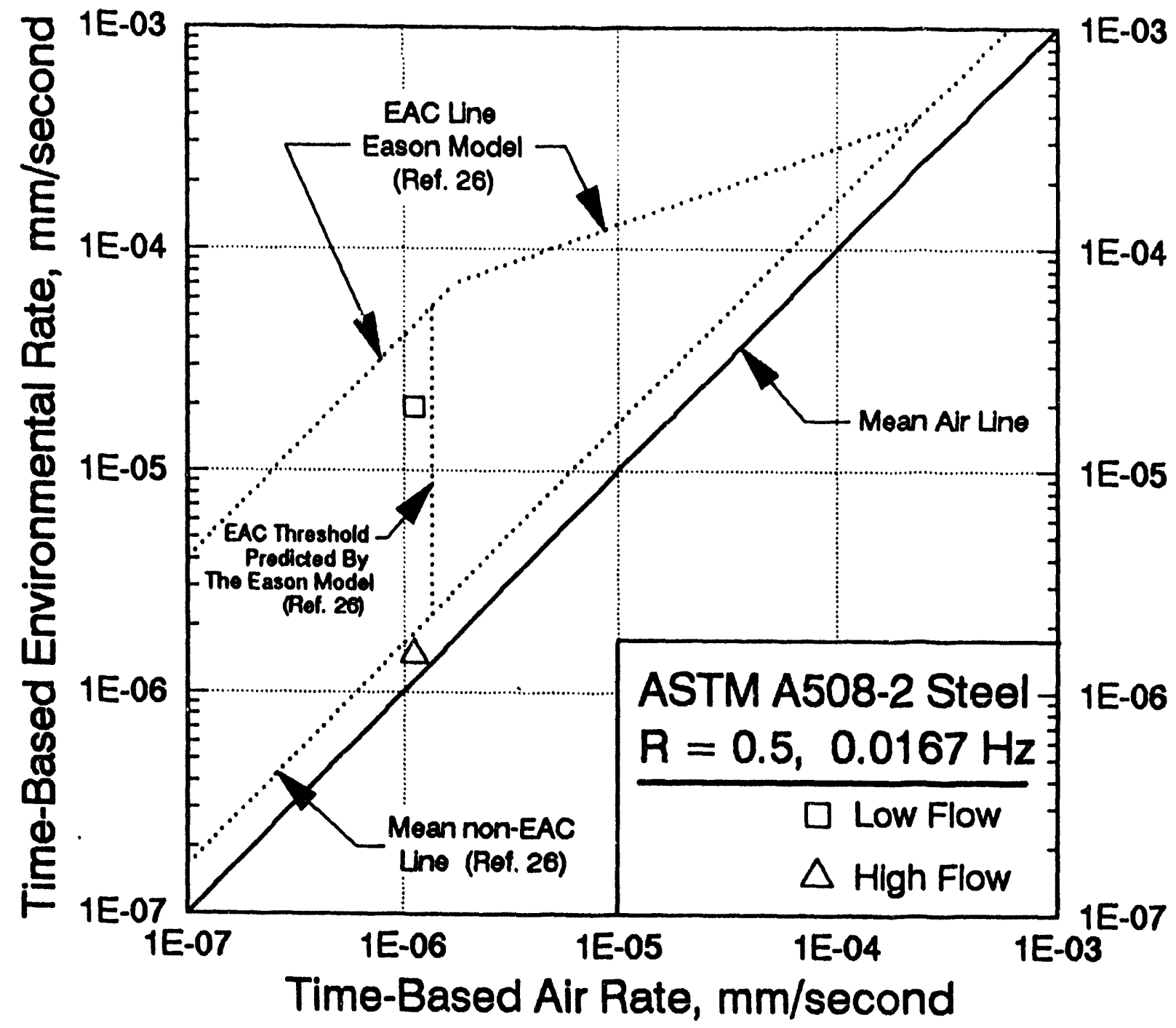

PAPER13

Figure 4. Time-domain plot of results reported in Reference 25 for the effect of water flow rate from the EAC response of a 0.017 (S $>0.022 \%$ A508-2 steel in a BWR environment $(400 \mathrm{ppb} \mathrm{O})$ at $240^{\circ} \mathrm{C}$. 


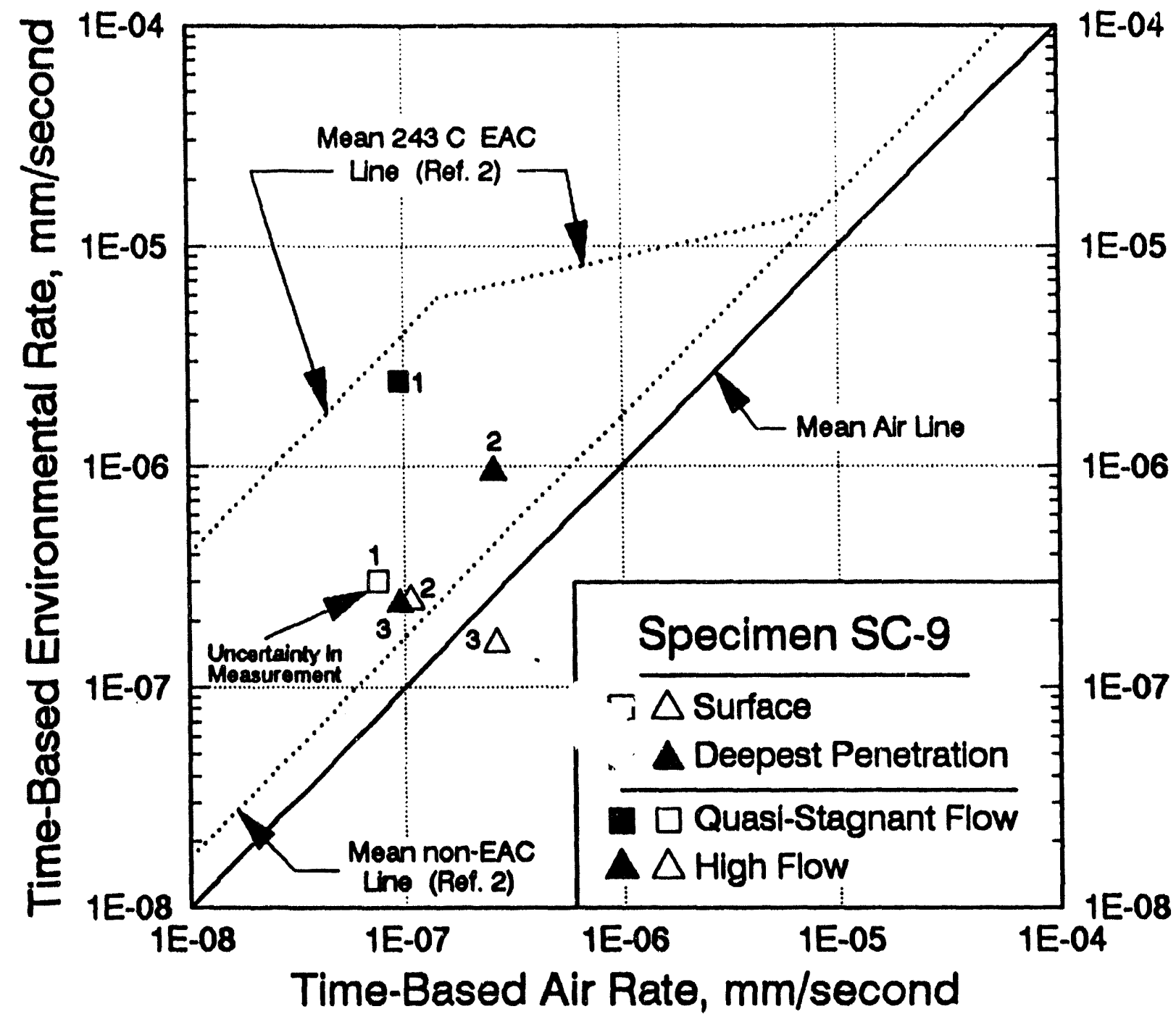

PAPER14

Figure 5. Time-domain plot of the experiment conducted on Specimen SC-9 to study the effect of high water flow rate upon EAC at $243^{\circ} \mathrm{C}$. Numbers associated with data points denote the sequential order of testing: " 1 " = quasi-stagnant phase, " 2 " = first high flow phase, " $3^{\prime}=$ second high flow phase. 


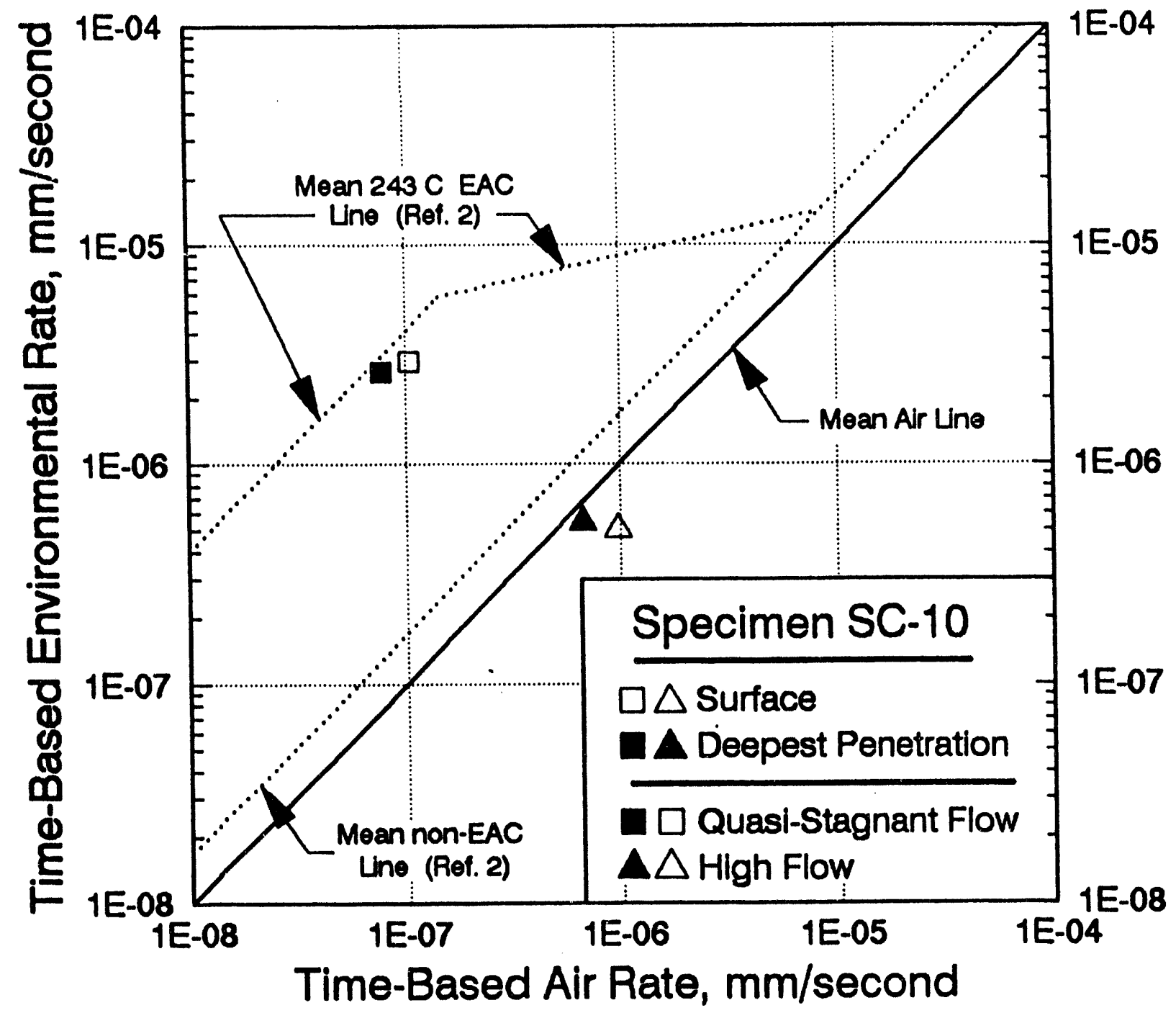

PAPER9

Figure 6. Time-domain plot of the experiment conducted on Specimen SC-10 to study the effect of high water flow rate upon EAC at $243^{\circ} \mathrm{C}$. 


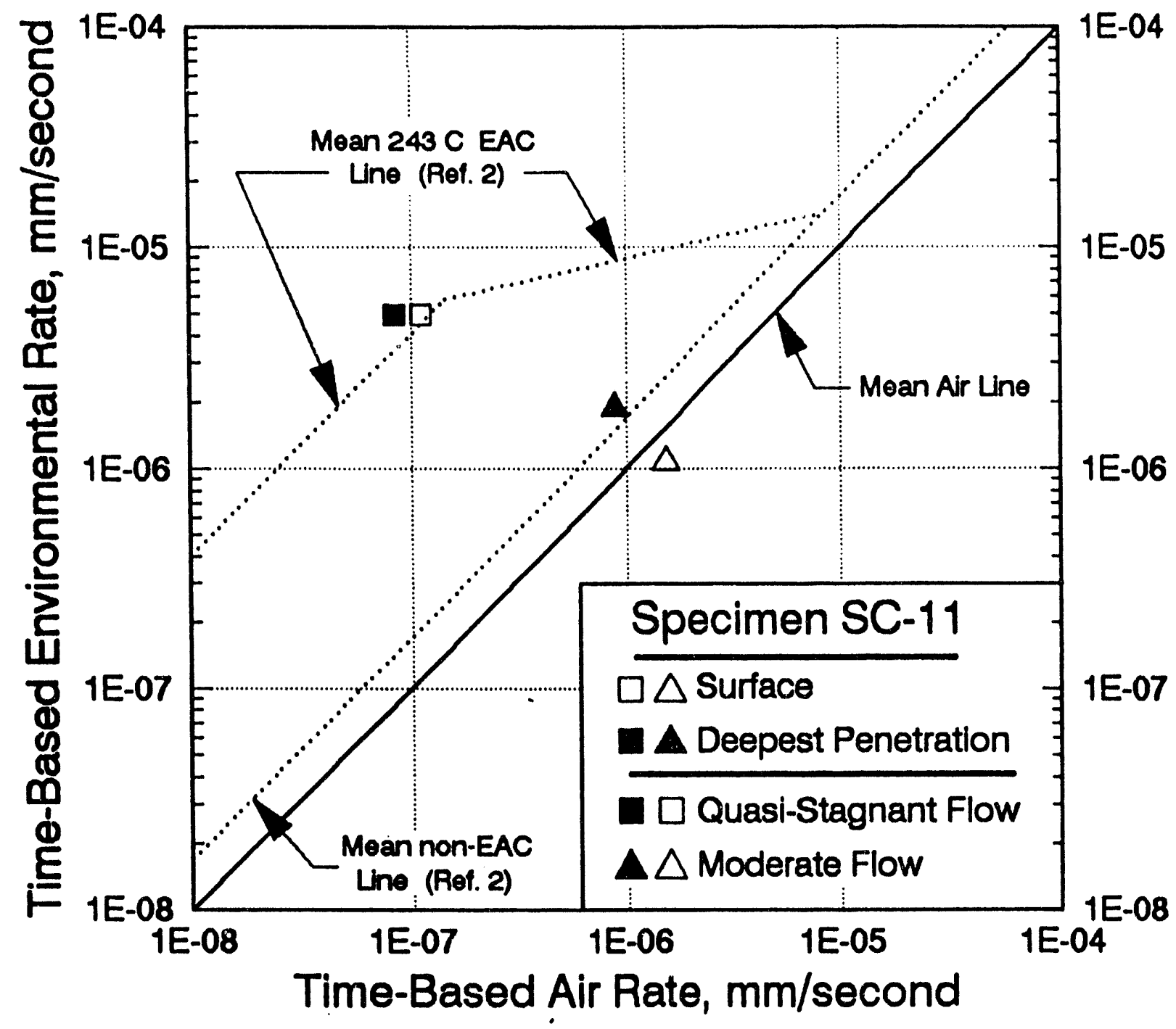

PAPER10

Figure 7. Time-domain plot of the experiment conducted on Specimen SC.11 to study the effect of moderate water flow rate upon EAC at $243^{\circ} \mathrm{C}$. 


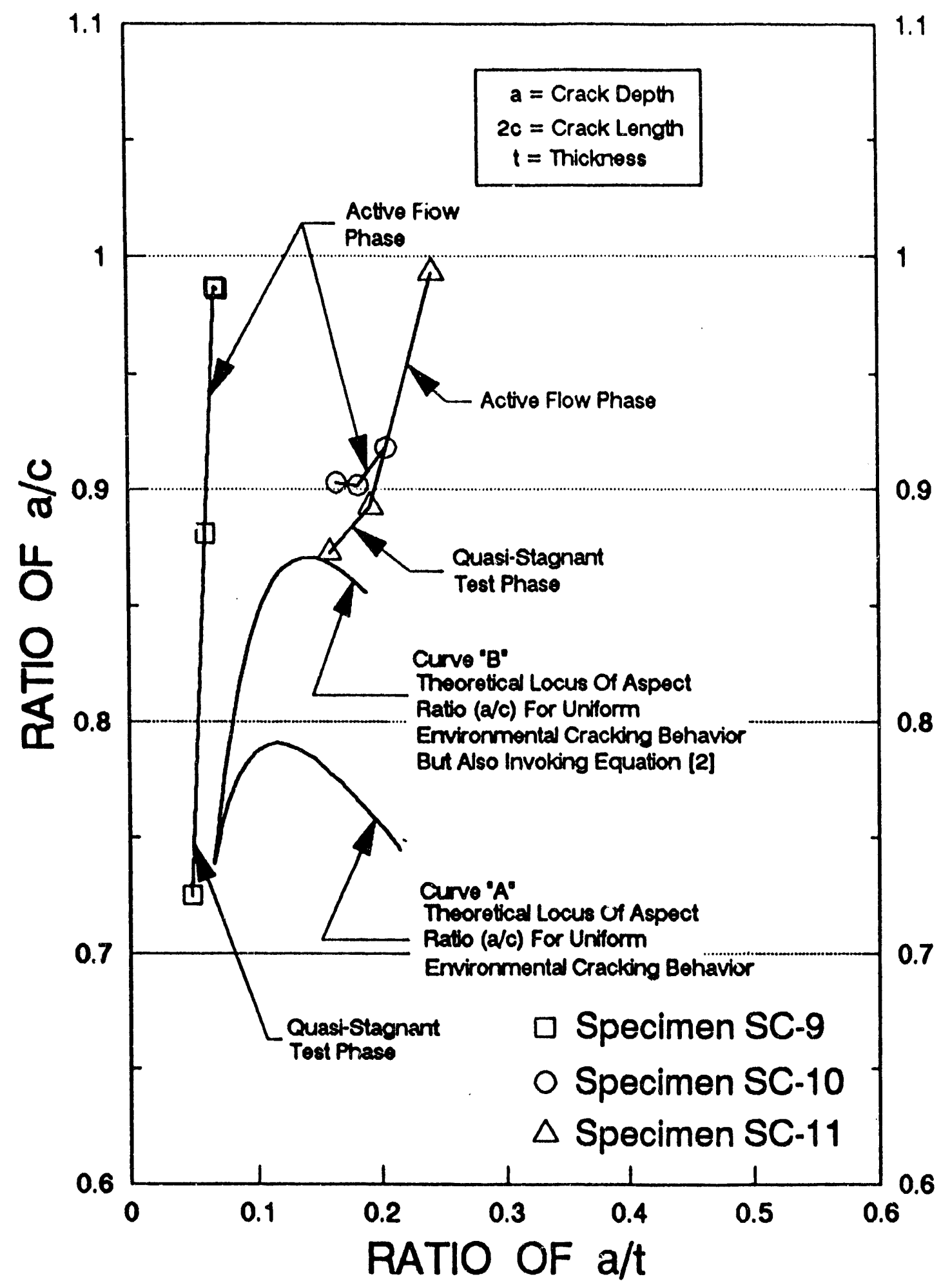

FLOW-3M

Figure 8. Comparison of observed crack aspect ratios with those predicted assuming uniform environmental conditions along the entire crack periphery. 

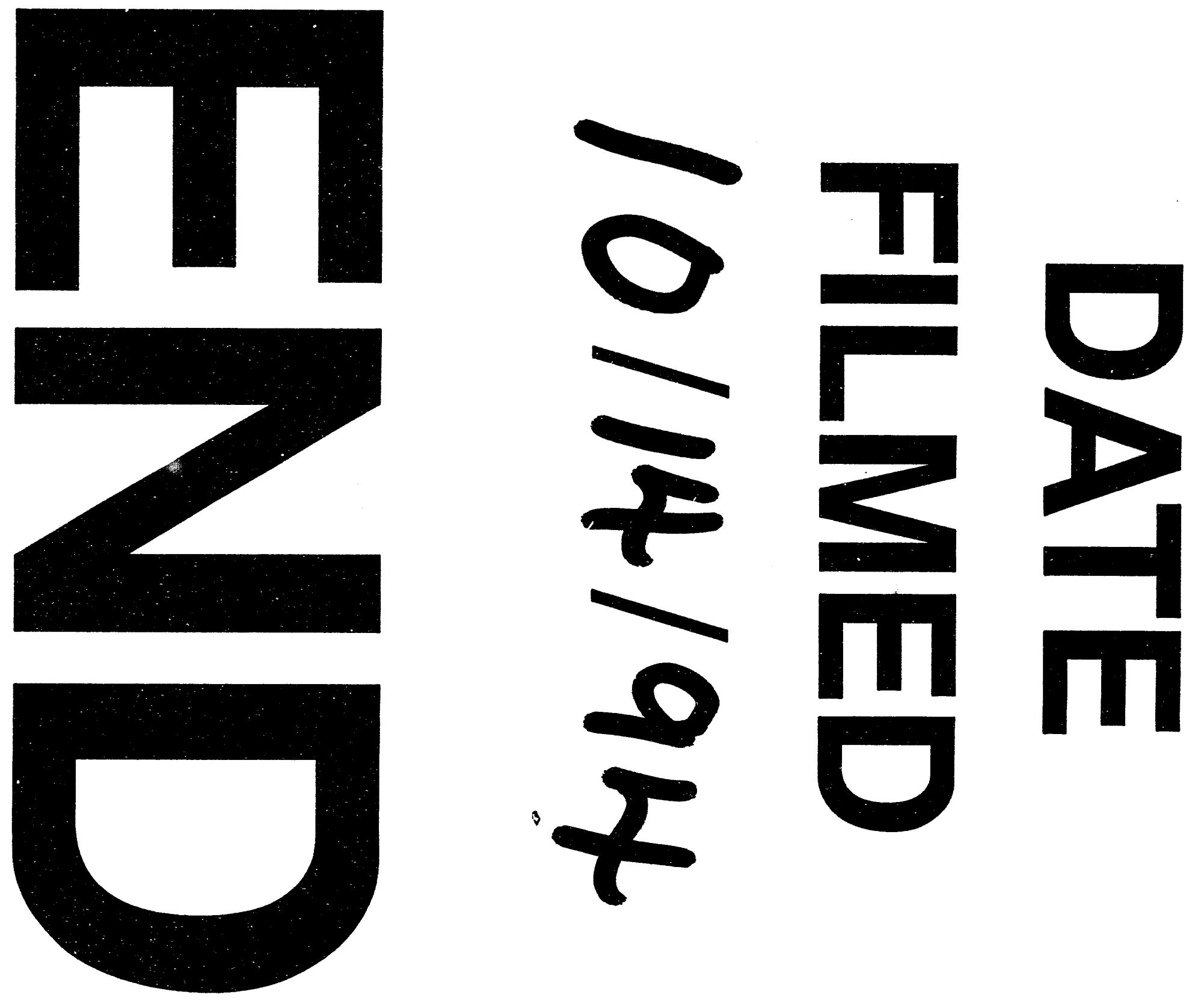
